\title{
Atypical Cystic Parotid Gland Acinic Cell Carcinoma in a Child
}

\author{
Noah N. Chasen, Peter Kalina \\ Department of Radiology, Mayo Clinic, Rochester, USA \\ Email: chasen.noah@mayo.edu
}

Received December 1, 2012; revised January 5, 2013; accepted January 15, 2013

Copyright (C) 2013 Noah N. Chasen, Peter Kalina. This is an open access article distributed under the Creative Commons Attribution License, which permits unrestricted use, distribution, and reproduction in any medium, provided the original work is properly cited.

\begin{abstract}
Purpose: To describe the extremely rare occurrence of acinic cell carcinoma of the parotid in a young child. Materials \& Methods: A 14-year-old boy presented with a left sided facial mass. It was initially thought to be a bug bite or perhaps a wrestling injury. However, it progressed rapidly overall several weeks. CT revealed a well-circumscribed, cystic, $3.9 \times 2.8 \times 3.2 \mathrm{~cm}$ mass centered in the deep lobe of the left parotid gland, also involving the superficial lobe and extending medially through the stylomandibular tunnel with a component extending to the stylomastoid foramen. There was no solid enhancing portion. There were several enlarged level II lymph nodes suspicious for nodal metastases. Results: The mass was biopsied and pathology was consistent with acinic cell carcinoma. Complete left parotidectomy and left selective neck dissection was performed, confirming the diagnosis. Conclusions: Salivary gland neoplasms are rare in children. Less than $5 \%$ of salivary gland tumors occur in children. Salivary gland neoplasms account for less than $8 \%$ of pediatric head and neck tumors. Approximately 1/3 of salivary gland tumors arising in childhood are malignant; most being mucoepidermoid. Acinic cell carcinoma of the parotid gland in children is extremely rare, especially in those under age 16, with only a few available case reports. This case was also unusual in that the lesion was predominantly cystic.
\end{abstract}

Keywords: Acinic Cell Carcinoma; Parotid Gland; Salivary Gland Tumors

\section{Introduction}

Salivary gland tumors are exceedingly rare in childhood with an annual incidence of this malignancy of 0.8 per million. The majority are located in the parotid gland. Less than $50 \%$ of salivary gland malignancies occur in children under the age of 15, and Acinic Cell Carcinoma accounts for about 35\% of all salivary gland malignancies [1]. We present a case of a predominately cystic Acinic Cell Carcinoma of the parotid gland, which presented in a 14-year-old boy.

\section{Case Report}

A 14-year-old boy developed a rapidly growing mass on the left side of his face near his ear, which was initially though to represent a bug bite or secondary to a wrestling injury. Because of the rapid growth over a period of months, medical attention was sought. Initial fine needle aspiration indicated acinic cell carcinoma. The patient obtained a CT scan with contrast, which showed a $3.9 \times$ $2.8 \times 3.2 \mathrm{~cm}$ mass centered in the deep lobe of the left parotid gland. The lesion contained a substantial cystic component, no enhancing solid components, and extended through the stylomandibular tunnel (Figure 1). In addition, there were several enlarged left sided level II jugular chain lymph nodes, which were concerning for metastasis (Figure 2). The patient underwent surgical resection of the lesion with complete left parotidectomy and selective lymph node resection (Figure 3). Gross resection confirmed the large cystic component of the mass and pathology confirmed acinic cell carcinoma with clear margins. No evidence of metastasis was found in the resected jugulodigastric lymph nodes.

\section{Discussion}

Malignant salivary gland tumors such as acinic cell carcinomas usually present as a painless enlarging mass with or without cervical lymphadenopathy. Facial nerve abnormality or lymph node metastasis on initial presentation is uncommon. Detection of salivary gland tumors in children is important because the incidence of malignancy is between $16 \%$ - 50\% [2].

Salivary gland tumors in children are rare with the 


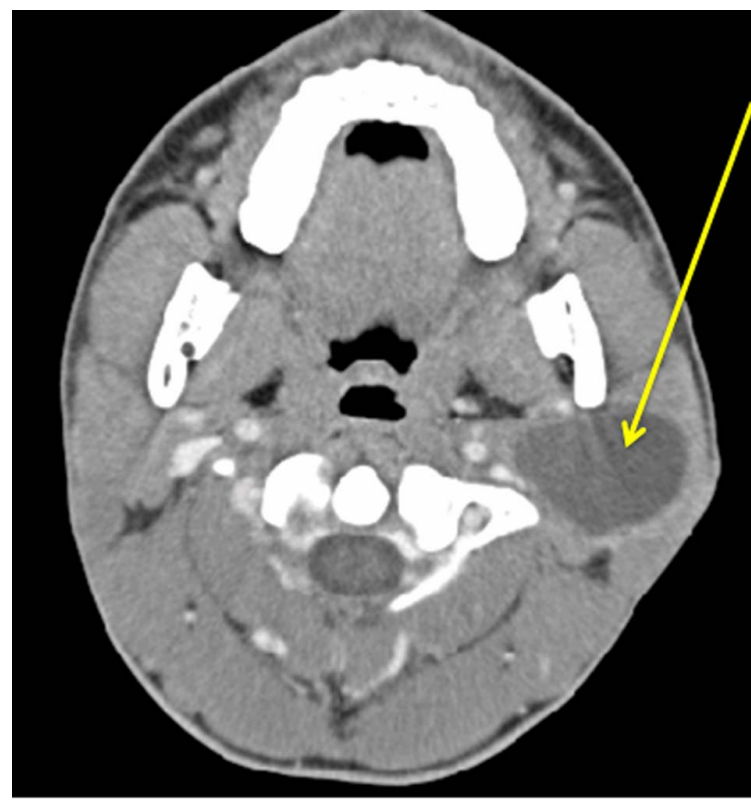

(a)

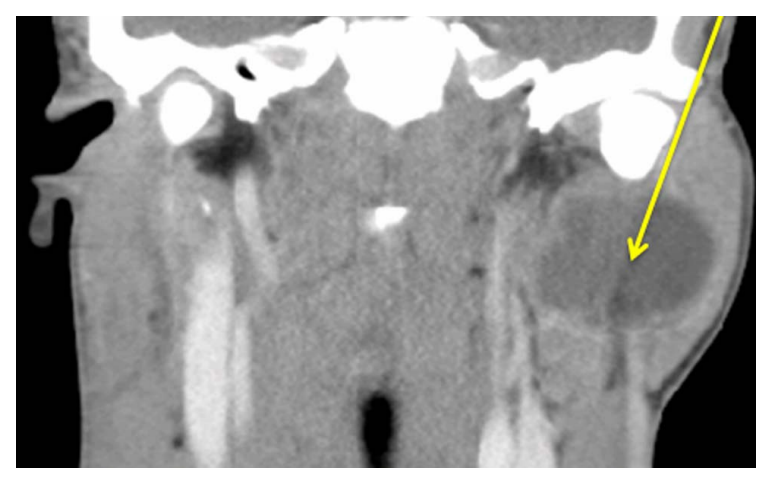

(b)

Figure 1. Cystic neoplasm involving the superficial and deep lobes of the left parotid gland on axial (a) and coronal (b).

most common malignancy being mucoepidermoid carcinoma, representing approximately 50\%. Acinic cell carcinoma is the second most common and represents about $35 \%$. Approximately $1 / 3$ of the acinic cell carcinomas occur in children between the ages of 10 and 14. Other malignant salivary gland neoplasms, which are less common include, adenoid cystic, adenocarcinoma, and primary squamous cell carcinoma [1]. Only 35 cases of acinic cell carcinoma of the parotid gland have been reported in children under the age of 16 [3]. Approximately $83 \%$ of acinic cell carcinomas occur in the parotid gland. Of the acinic cell cancers of the parotid, approximately $23 \%$ are cystic or cystic with a mural nodule [4].

Both CT and MRI provide valuable information prior to surgery. Although MRI remains more accurate concerning the investigation of potential malignant disease, CT is more widely available [5]. Fine needle aspiration is an appropriate modality for diagnosis of parotid lesions if

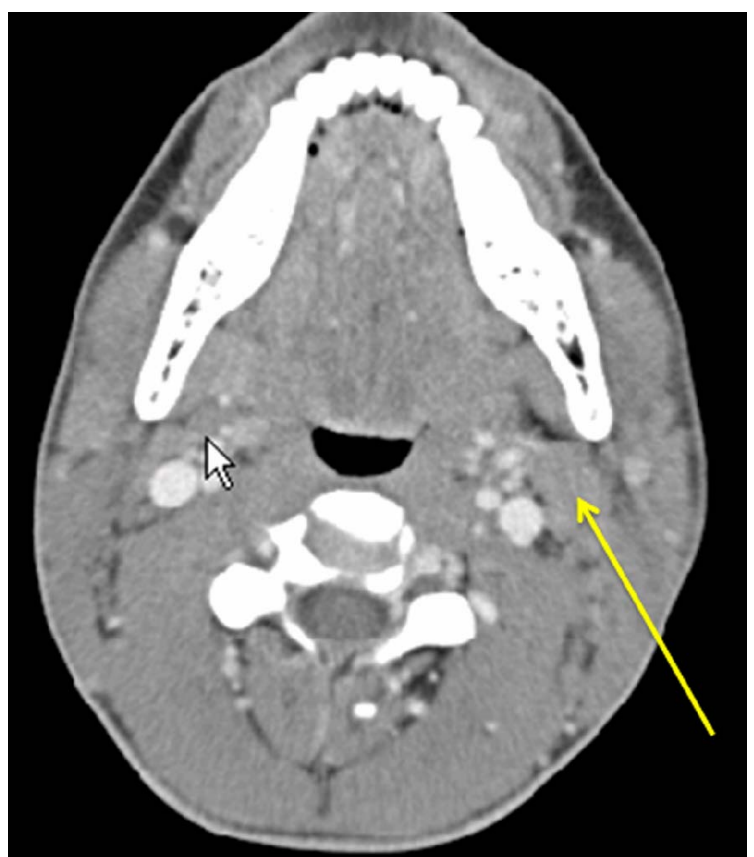

(a)

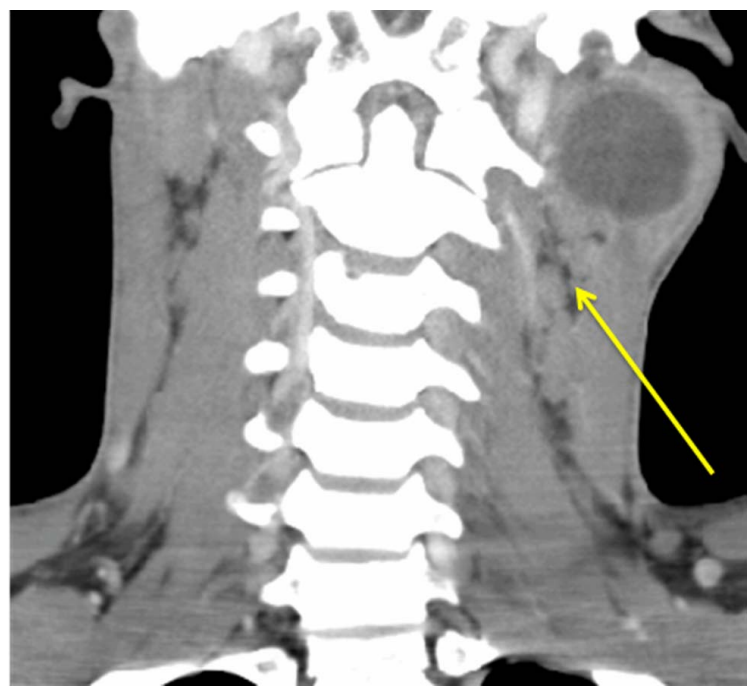

(b)

Figure 2. Axial (a) and coronal (b) CT with contrast shows enlarged jugulodigastric nodes ipsilateral to the mass.

the probability of malignancy is low. The reason concerns the relative high frequency of false negative results or low sensitivity for FNA in comparison to specificity and accuracy. The high accuracy of FNA is mostly useful for broad classification of benign versus malignant etiology. However, when a more precise diagnosis is required, accuracy declines. Acinic cell carcinomas are often misdiagnosed by FNA for a benign salivary gland tumor [6]. Therefore, lobectomy for superficial lobe involvement only and total parotidectomy for involvment of the deep lobe with preservation of the facial nerve is appropriate [7]. The use of adjuvant radiotherapy is con- 


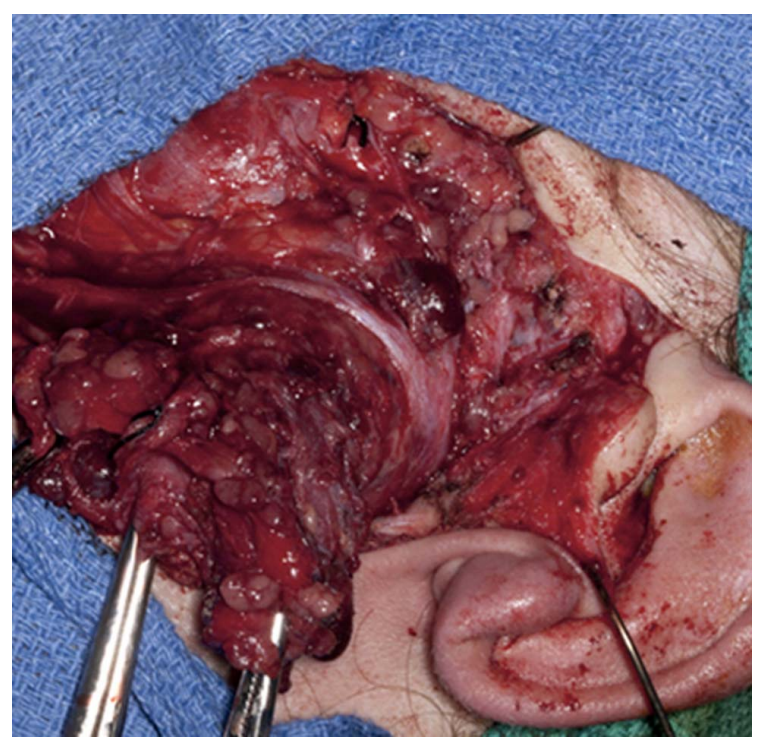

(a)

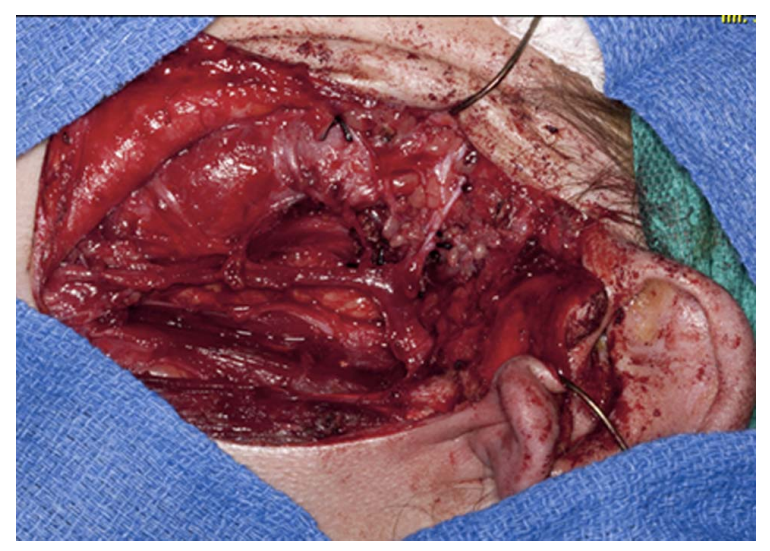

(b)

Figure 3. Pre-resection (a) and post-resection (b) operative photographs.

troversial. However, a recent 1241 case retrospective study of radiotherapy for Acinic cell carcinoma by Andreoli [8] indicates that there was no statistical differences in overall survival for stages I through 4.

Initial fine needle aspiration was appropriate for this 14-year-old boy with a left facial mass because of the low incidence of salivary gland tumors in children, and the clinical features of a rapidly growing mass. The use of CT was appropriate for surgical planning prior to his total parotidectomy and lymph node resection. This case of pathologically proven cystic acinic cell carcinoma is particularly rare because only one third occur in children between 10 - 14, and only 23\% of acinic cell cancer in the parotid gland is cystic.

\section{REFERENCES}

[1] I. Sultan, C. Rodriguez-Galindo, S. Al-Sharabati, M. Guzzo, M. Casanova and A. Ferrari, "Salivary Gland Carcinomas in Children and Adolescents: A Population-Based Study, with Comparison to Adult Cases,” Head \&Neck, Vol. 33, No. 10, 2011, pp. 1476-1481.

[2] P. Michail, I. Karavokyros, E. Pikoulis, A. Arvelakis, G. Charminis, O. Michail and D. Theodoros, “Acinic Cell Carcinoma of the Parotid Gland in Children: A Case Report and Literature Review," West Indian Medical Journal, Vol. 57, No. 1, 2008, pp. 70-72.

[3] F. M. Tucci, P. M. Bianchi, S. Bottero, P. Partipilo and V. Pierro, "Acinic Cell Carcinoma of the Parotid Gland in Childhood,” International Journal of Pediatric Otorhinolaryngology, Vol. 27, No. 2, 1993, pp. 187-191. doi:10.1016/0165-5876(93)90135-P

[4] S.-I. Suh, H. Y. Seol, T.-K. Kim, N. J. Lee, J. H. Kim, K. Ah Kim, J.-S. Woo and J. H. Lee, "Acinic Cell Caricinoma of the Head and Neck Radiologic and Pathologic Correlation,” Journal of Computed Assisted Tomography, Vol. 29, No. 1, 2005, pp. 121-126. doi:10.1097/01.rct.0000150141.14113.ab

[5] C. Rainea, K. Salibab, A. J. Chippindaleb and N. R. McLeana, "Radiological Imaging in Primary Parotid Malignancy,” The British Association of Plastic Surgeons, Vol. 56, No. 7, 2003, pp. 637-643. doi:10.1016/S0007-1226(03)00358-8

[6] H. H. Alphs, D. Eisele and W. Westra, "The Role of Fine Needle Aspiration in the Evaluation of Parotid Masses," Current Opinion in Otolaryngology \& Head and Neck Surgery, Vol. 14, No. 2, 2006, pp. 62-66. doi:10.1097/01.moo.0000193184.38310.0a

[7] J. M. Levin, D. W. Robinson and F. Lin, "Acinic Cell Carcinoma Collective Review Including Bilateral Cases," Archives of Surgery, Vol. 110, No. 1, 1975, pp. 64-68. doi:10.1001/archsurg.1975.01360070064011

[8] M. T. Andreoli, S. M. Andreoli, M. G. Shrime and A. K. Devaiah, "Radiotherapy in Parotid Acinic Cell Carcinoma. Does It Have an Impact on Survival," Archives of Otolaryngology—Head and Neck Surgery, Vol. 138, No. 5, 2012, pp. 463-466. 